\section{Effects of sensorimotor training on pelvic stability and balance in runners}

\author{
Efeitos do treinamento sensório- \\ motor na estabilidade pélvica \\ e no equilíbrio de corredores
}

Letícia Jonas de Freitas (D) *

Sharon Moreira Ignácio (1)

Thatia Regina Bonfim (D)

Pontifícia Universidade Católica de Minas Gerais (PUC Minas), Poços de Caldas, MG, Brazil

Date of first submission: April 30, 2021

Last received: July 20, 2021

Accepted: September 21, 2021

Associate editor: Ana Paula Cunha Loureiro

*Correspondence: leticiajfreitas@hotmail.com

\begin{abstract}
Introduction: Running has increased significantly in recent years due to its benefits and practicality. However, like any sport, running poses a risk of injury, leading to the need for clinical intervention and even its practitioners quitting the sport. Therefore, preventive strategies seeking to minimize the occurrence and consequences of such risk factors in these athletes are pivotal. Objective: To investigate the preventive effects of a sensorimotor training protocol on the balance and pelvic stability of runners. Methods: The study sample consisted of fourteen 10-km runners of both genders divided into two groups: the control group (CG) and the sensorimotor training group (SMTG). Both groups were evaluated using the single-leg stance test (static balance), Trendelenburg test (pelvic stability), and hop test (dynamic balance). The SMTG underwent 16 interventions, while the CG did not receive any intervention. Results: The SMTG showed a significant increase in the permanence time of the single-leg stance test $(p<0.05)$ and a reduction in knee valgus during impulse and landing moments of the single hop test only in the right lower $\operatorname{limb}(p<0.05)$, while the CG showed no significant difference in all tests applied ( $p>0.05$ ). Regarding pelvic stability, there was no significant difference in any of the groups. Conclusion: The proposed protocol significantly improved the static balance of the SMTG, but not the pelvic stability.
\end{abstract}

Keywords: Injuries in athletes. Prevention. Proprioception. Running. 


\section{Resumo}

Introdução: A prática de corrida aumentou significa-tivamente nos últimos anos devido aos seus benefícios e sua praticidade. Como qualquer esporte, no entanto, a corrida de rua oferece risco de lesões, que podem acarretar a necessidade de intervenção clínica e até mesmo o afastamento de seus praticantes. Dessa forma, tornam-se essenciais estratégias preventivas que busquem minimizar a ocorrência e as consequências de tais fatores de riscos nestes atletas. Objetivo: Investigar o efeito preventivo de um protocolo de treinamento sensório-motor no equilíbrio e na estabilidade pélvica de atletas corredores de rua. Métodos: $A$ amostra deste estudo foi composta por 14 atletas corredores de rua de $10 \mathrm{~km}$, de ambos os sexos, divididos em dois grupos: grupo controle (GC) e grupo treinamento sensório-motor (GTSM). Ambos os grupos foram avaliados por meio do teste de apoio unipodal (equilibrio estático), teste de Trendelenburg (estabilidade pélvica) e hop test simples (equilíbrio dinâmico). O GTSM foi submetido a 16 intervenções, enquanto o GC não recebeu nenhuma. Resultados: O GTSM apresentou aumento significativo no tempo de permanência do teste de apoio unipodal $(p<0,05)$ e redução do valgo de joelho durante os momentos de impulso e de aterrissagem do hop test simples somente no membro inferior direito $(p<0,05)$. O GC não apresentou diferença significativa em nenhum dos testes aplicados $(p>0,05)$. Em relação à estabilidade pélvica, não houve diferença significativa em nenhum dos grupos.Conclusão: O protocolo proposto promoveu melhora sobretudo do equilíbrio estático dos atletas do GTSM, mas não na estabilidade pélvica.

Palavras-chave: Lesões em atletas. Prevenção. Propriocepção. Corrida.

\section{Introduction}

The search for a healthy lifestyle and a better quality of life are goals present in the reality of numerous individuals. For these reasons, there is an increasing demand for regular physical exercise, especially aerobic exercise, among which street running stands out due to its practicality, low cost, and the multiple body benefits generated, such as lower risk of cardiovascular disease. ${ }^{1}$

As in any other sport modality, however, street running exposes practitioners to the risk of injuries, and anywhere from 19.4 to $92.4 \%$ of musculoskeletal changes occur in the lower limbs of runners, ${ }^{2,3}$ especially in the ankle/foot, knee, and hip joints. ${ }^{2-4}$ These changes may contribute to injuries at these sites, especially if there are sensorimotor deficits, including more significant postural sway and/or joint misalignment. ${ }^{5}$

Moreover, such injuries can be severe enough to reduce or even keep athletes from practicing sports, in addition to leading to the need for medical care. ${ }^{1}$ Hence, the use of preventive interventions to reduce the incidence and impact of these injuries among runners is pivotal. In this scenario, physiotherapy uses a vital resource used in the sports environment: sensorimotor training, which aims to improve proprioception and muscle response, improving dynamic joint stability and, consequently, reducing the risk of injuries. ${ }^{6}$

As a result, given the risk of injuries in sports and the need for preventive measures that seek not only to reduce the impact of these injuries but also improve the performance of street runners, this study aimed to investigate the effects of a sensorimotor training protocol on the dynamic and static balance and pelvic stability of street runners.

\section{Methods}

\section{Sample}

The sample was composed of fourteen $10-\mathrm{km}$ street runners (eight men and six women) who signed the informed consent form. As established by the National Health Council on ethical guidelines for research with human subjects, this study was approved by the Research Ethics Committee of the Pontifical Catholic University of Minas Gerais (CAAE: 7697.1617.9.0000.5137).

After selecting participants who met the inclusion criteria, the first eight participants were randomly assigned to two groups. Then, to have a homogeneous distribution between the groups, the remaining participants were paired by sex, age, body mass, and height. The participants were thus divided into two groups, each composed of four men and three women: the control group (CG), with a mean age of 47.1 years ( \pm 15.8 ), mean height of $166 \mathrm{~cm}( \pm 9.7)$, and mean body mass of $64.1 \mathrm{~kg}( \pm 9.9)$, and the sensorimotor training group (SMTG), with a mean age of 41.9 years ( \pm 12.5$)$, mean height of $171.3 \mathrm{~cm}( \pm 9.3)$, and mean body mass of $74.9 \mathrm{~kg}( \pm 10)$.

To meet the inclusion criteria, the participants needed to be over 18 years old, regularly practice street running, frequently attend training sessions, and agree with the 
objectives and procedures of the study. The exclusion criteria were recent injury to the musculoskeletal system with inflammatory signs and neurological disorders. The participants were submitted to an anamnesis for sample characterization, addressing the following items: age, sex, body mass, height, sports practice, and history of injuries based on the individuals' perception of injury. Both groups were equally evaluated in the initial and final evaluations using the single-leg stance test for static balance, the Trendelenburg test for pelvic stability, and the hop test for dynamic balance. For the Trendelenburg and hop tests, spherical markers were placed on the anterosuperior iliac spines, the midpoint of the patella, and the lateral and medial malleoli; the latter were used to identify the center of the ankle joint. The images were acquired using a 16-megapixel digital camera (ASUS ZenFone 4 smartphone, model ZE554KL). These images were later analyzed by biophotogrammetry using the Kinovea ${ }^{\circledR}$ software (version 0.8.15; Windows XP) for the sub-items "pelvic stability" and/or "dynamic balance."

\section{Static balance}

The static balance was evaluated using the singleleg stance test, in which the athlete remained on one leg with their eyes closed and their upper limbs crossed over the trunk for 30 seconds. The task was interrupted when the participant did not maintain a stable posture, and the maximum time achieved was recorded. ${ }^{7}$ Two trials were performed for each lower limb, and the mean time spent in both trials was considered the dependent variable.

\section{Pelvic stability}

The pelvic stability was evaluated using the Trendelenburg test and performed similarly to the single-leg stance test, although the participants kept their eyes open. After 30 seconds, the participant was photographed and the pelvic alignment was observed. ${ }^{8}$ The positive sign was considered according to the contralateral pelvic drop for the supporting lower limb, where an elevation of the ipsilateral pelvis of this limb occurs, $^{8,9}$ and therefore, the use of the angulation measurement between the iliac spines was determined. The dependent variable was the joint angle of the lower limb (anterosuperior iliac spine, midpoint of the patella, and center of the malleoli), where closer to $180^{\circ}$ indicated greater joint alignment.

\section{Dynamic equilibrium}

In the single-leg hop test, ${ }^{9}$ we attempted to analyze the knee valgus angle (anterosuperior iliac spine, midpoint of the patella, and midpoint between the malleoli), which was considered the dependent variable since knee valgus is considered the medial displacement of the knee beyond the thigh-foot alignment. ${ }^{10}$ The analysis was performed by video in two moments: impulsion (the instant of completing the single-leg squat; moment 1) and landing (the instant when the entire sole of the foot touched the ground; moment 2), where closer to $180^{\circ}$ indicated greater joint alignment.

\section{Sensorimotor training protocol}

After the initial evaluation, the CG did not receive any intervention for eight weeks, while the SMTG had sixteen 30-min physiotherapeutic interventions twice a week. Each intervention consisted of joint warm-ups and muscle stretching for $10 \mathrm{~min}$ and sensorimotor training for $20 \mathrm{~min}$. The warm-up occurred through active muscle stretching exercises and joint movements of the trunk, hips, knees, and ankles. The sensorimotor training was divided into two 10-min sessions.

Session 1 emphasized balance, proprioception, and lumbopelvic stability training through exercises that stimulated balance reactions on unstable surfaces with different perturbations (Figure 1). On the proprioceptive disk, the athletes were instructed to remain as stable as possible ( $3 \times 30 \mathrm{~s})$, and on the balance board and with the same instructions, the athletes threw a $2 \mathrm{~kg}$ ball to the therapist ( $3 \times 10$ repetitions).

Session 2 emphasized training agility, coordination, and landing on the ground through different speed exercises, changes in direction, sudden stops, and landing on unstable surfaces (Figure 1). For the agility and coordination training, the participants were instructed to perform the exercises as quickly as possible while maintaining their lower limbs aligned ( 3 × $30 \mathrm{~s}$ ). For the landing exercise, the athletes were instructed to perform the exercises as quickly and stably as possible ( $3 \times 10$ repetitions).

The sensorimotor training protocol progressively became more difficult every four interventions (Table 1). After the sixteen interventions, both groups were submitted to a final evaluation (identical to the initial one) to investigate and compare the effects of the training. 


\section{Data analysis}

Statistical analysis was performed by $2 \times 2$ analysis of variance (ANOVA) with repeated measures using both groups (CG $\times$ SMTG) and evaluations (initial $\times$ final) as factors, followed by Bonferroni post hoc tests to identify any differences between the groups, evaluations, and interactions between groups and evaluations. Data normality was tested using the Shapiro-Wilk test and homogeneity of variance using the Levene test. The length of stay (in seconds) in the single-leg stance test and the joint angles in the Trendelenburg and hop tests were considered dependent variables. All statistical procedures were carried out using the statistical package SPSS Statistics (version 22; IBM SPSS Statistics $\left.{ }^{\circledR}\right)$, considering the significance level of 0.05 .

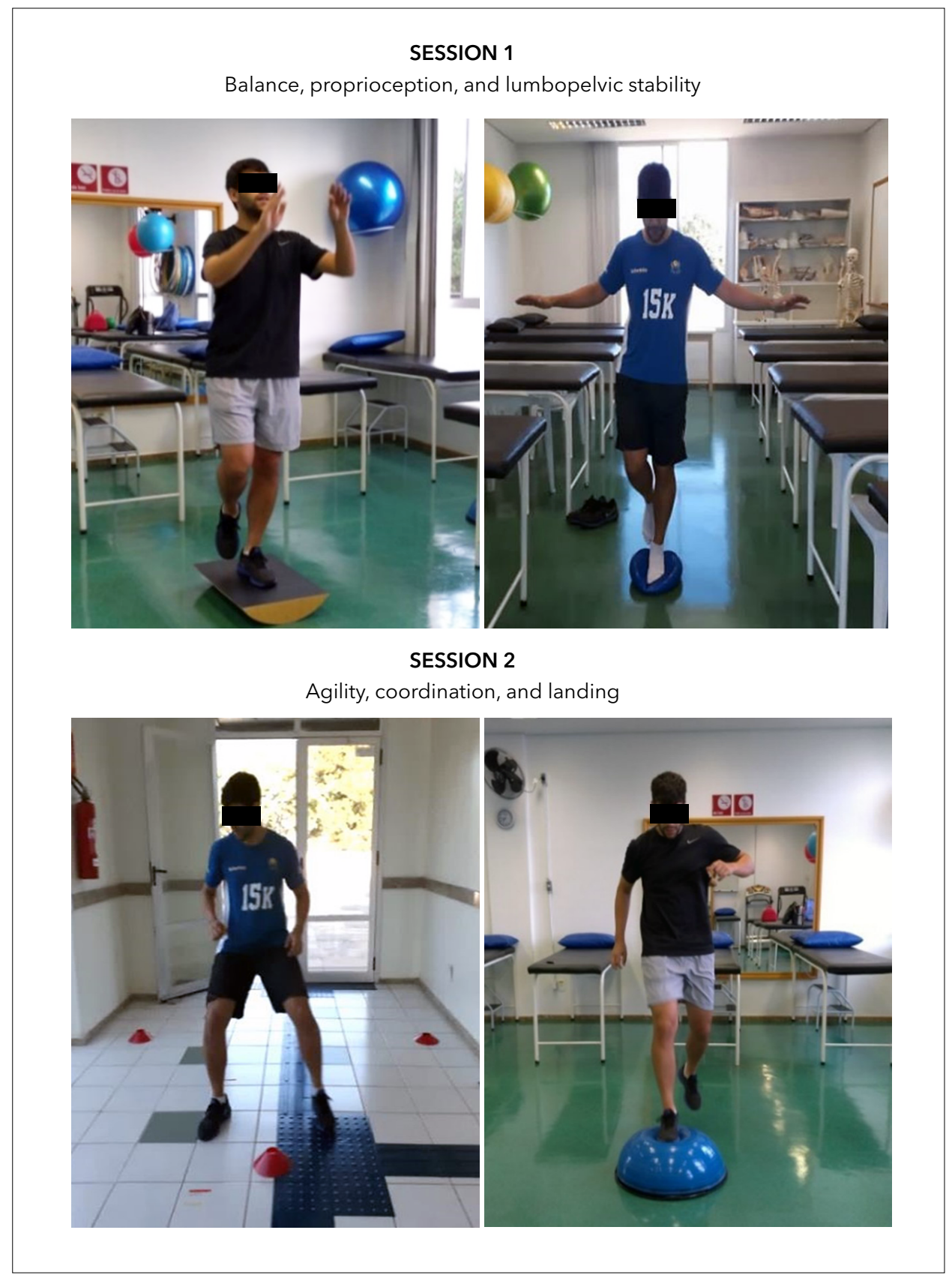

Figure 1 - Demonstration of the sensorimotor training. 
Table 1 - Evolution of the sensorimotor training protocol

\begin{tabular}{|c|c|c|c|}
\hline \multicolumn{2}{|l|}{ Session 1} & \multicolumn{2}{|r|}{ Session 2} \\
\hline Proprioceptive disk & $\begin{array}{l}\text { Double-leg stance, eyes open } \\
\text { Double-leg stance, eyes closed } \\
\text { Single-leg stance, eyes open } \\
\text { Single-leg stance, eyes closed }\end{array}$ & Agility & $\begin{array}{l}\text { Anterior and posterior displacement } \\
\text { Anterior and posterior displacement + elastic strap } \\
\text { Multi-directional displacement (AP - ML - LM - PA) } \\
\text { Multi-directional displacement + elastic strap }\end{array}$ \\
\hline \multirow[t]{2}{*}{ Balance board } & $\begin{array}{l}\text { Double-leg stance, AP direction, } \\
2 \mathrm{~kg} \text { ball } \\
\text { Single-leg stance, AP direction, } \\
2 \mathrm{~kg} \text { ball }\end{array}$ & Coordination & $\begin{array}{l}\text { Anterior displacement between cones } \\
\text { Lateral displacement between cones } \\
\text { Anterior displacement + lower limb elevation } \\
\text { Lateral displacement + lower limb elevation }\end{array}$ \\
\hline & $\begin{array}{l}\text { Double-leg stance, ML direction, } \\
2 \mathrm{~kg} \text { ball } \\
\text { Single-leg stance, ML direction, } \\
2 \mathrm{~kg} \text { ball }\end{array}$ & $\begin{array}{l}\text { Landing } \\
\text { (Bosu) }\end{array}$ & $\begin{array}{l}\text { Single-leg jumping } \\
\text { Double-leg jumping } \\
\text { Running and double-leg landing } \\
\text { Running and single-leg landing }\end{array}$ \\
\hline
\end{tabular}

Note: $\mathrm{AP}=$ anteroposterior; $\mathrm{ML}=$ mediolateral; $\mathrm{LM}=$ lateromedial; $\mathrm{PA}=$ posteroanterior .

\section{Results}

Most of the participants in this sample (35.7\%) had an average street running experience of 1 to 3 years and reported injuries related to the sport and withdrawal from the sport (Table 2).

Table 2 - Practice time and athlete injury history in the sensorimotor training group (SMTG) and the control group (CG)

\begin{tabular}{lcc}
\hline & CG $(\mathrm{n}=7)$ & SMTG $(\mathrm{n}=7)$ \\
\hline Time practicing the sport & $\mathbf{n}(\%)$ & $\mathbf{n}(\%)$ \\
1-3 years & $1(14.3)$ & $4(57.1)$ \\
3-5 years & $2(28.6)$ & $1(14.3)$ \\
5-8 years & $2(28.6)$ & $0(0.0)$ \\
8-10 years & $1(14.3)$ & $0(0.0)$ \\
$>10$ years & $1(14.3)$ & $2(28.6)$ \\
History of injury & $5(71.4)$ & $6(85.7)$ \\
Absence due to injury & $4(57.1)$ & $6(85.7)$ \\
$\begin{array}{l}\text { Absent and undergoing } \\
\text { physiotherapeutic treatment }\end{array}$ & $3(42.9)$ & $4(57.1)$ \\
Improvement after & & \\
physiotherapeutic treatment & $4(57.1)$ & $6(85.7)$ \\
\hline
\end{tabular}

\section{Static balance - Single-leg stance test}

For the time spent on the single-leg stance with eyes closed (in seconds), the statistical analysis indicated a significant difference between evaluations ( $p=0.001)$ and interaction evaluation and group ( $p=0.001)$, albeit there was no difference between groups ( $p=0.186$ ). The significant interaction indicates distinct behaviors in the groups. In this case, the time spent on the single-leg stance with eyes closed increased in the SMTG in both lower limbs; in the CG, it only increased in the right lower limb. The behavior of both groups in this test before and after the intervention is illustrated in Figure 2A. The mean and standard deviation for the length of stay in the right and left single-leg stance for both groups and assessments and $p$ values in the intergroup and intragroup analyses determined by the Bonferroni post hoc test are listed in Table 3.

The post hoc tests indicated that the CG and SMTG showed no significant difference for the length of stay in the right $(p=0.728)$ and left $(p=0.700)$ single-leg stance of the initial evaluation. Nonetheless, the post hoc tests indicated a significant difference between the CG and SMTG for the length of stay in the right $(p=0.05)$ and left $(p=0.019)$ single-leg stance of the final evaluation. Additionally, the post hoc analysis showed that the SMTG significantly increased in the static balance length of stay time in the right $(p=0.001)$ and left $(p=0.012)$ singleleg stance after eight weeks of the sensorimotor training protocol, which shows that this protocol had a positive effect on the static balance of street runners. For the CG, the post hoc tests did not show a significant difference for the length of stay in the left single-leg stance ( $p=$ 
0.798), although there was a significant increase in the length of stay in the right single-leg stance $(p=0.026)$, which is likely due to the learning effect in the test or by the right lower limb dominance.

\section{Pelvic stability - Trendelenburg test}

The joint angle represents the pelvic alignment, and the statistical analysis did not indicate any significant difference for the group $(p=0.474)$ and evaluation $(p=0.110)$, albeit there was a notable difference for the interaction between group and evaluation ( $p=$ 0.005). The interaction occurred due to the different behavior between the groups, whereby the joint angle decreased between the evaluations in the CG, while the joint angle increased in the SMTG, which indicates better pelvic alignment in this group after the proposed intervention (Figure 2B). Additionally, Table 3 shows the mean and standard deviation for the pelvic alignment of joint angles during the Trendelenburg test in both groups and evaluations, followed by the $p$ value of the intergroup and intragroup analyses using the Bonferroni post hoc test.

The post hoc tests indicated that the CG and SMTG did not present a significant difference for the joint angle in the right lower limb (RLL; $p=0.301)$ and left lower limb (LLL; $p=0.059$ ) in the initial evaluation. In the final evaluation, the CG and SMTG showed no significant difference in joint angle in the RLL ( $p=0.383$ ) and $L L L$ $(p=0.102)$. In addition, the post hoc tests indicated that the SMTG showed an increased joint angle in the RLL ( $p=0.012)$ and LLL ( $p=0.015)$ after eight weeks of the sensorimotor training protocol, thereby indicating better pelvic alignment. For the CG, the post hoc analysis did not show any significant difference for the joint angle in the RLL ( $p=0.094)$, indicating a significant reduction in the joint angle of the LLM ( $p=0.038)$, suggesting a worse pelvic alignment.

Table 3 - Mean and standard deviation of the athletes $(n=7)$ from the sensorimotor training group (SMTG) and the athletes $(n=7)$ from the control group (CG) in the initial evaluation (IE) and final evaluation (FE) for the lower limbs (right, RLL; left, LLL) and in the first (M1; impulsion) and the second moment (M2; landing) for the one-leg stance, Trendelenburg and hop tests

\begin{tabular}{|c|c|c|c|c|c|c|c|c|c|c|c|c|}
\hline \multicolumn{13}{|c|}{ Static balance (single-leg stance test) - in seconds } \\
\hline & \multicolumn{6}{|c|}{ RLL } & \multicolumn{6}{|c|}{ LLL } \\
\hline & \multicolumn{2}{|c|}{ Initial evaluation } & \multicolumn{2}{|c|}{ Final evaluation } & \multicolumn{2}{|c|}{$\mathrm{p}$ value } & \multicolumn{2}{|c|}{ Initial evaluation } & \multicolumn{2}{|c|}{ Final evaluation } & \multicolumn{2}{|c|}{ pvalue } \\
\hline SMTG & \multicolumn{2}{|c|}{$10.9( \pm 6.1)$} & \multicolumn{2}{|c|}{$28.9( \pm 2.0)$} & \multicolumn{2}{|c|}{$0.001 \ddagger^{\star}$} & \multicolumn{2}{|c|}{$15.7( \pm 10.9)$} & \multicolumn{2}{|c|}{$25.3( \pm 6.1)$} & \multicolumn{2}{|c|}{$0.012 \ddagger^{\star}$} \\
\hline CG & \multicolumn{2}{|c|}{$12.6( \pm 8.7)$} & \multicolumn{2}{|c|}{$19.9( \pm 11.1)$} & \multicolumn{2}{|c|}{$0.026 \ddagger^{\star}$} & \multicolumn{2}{|c|}{$15.4( \pm 10.3)$} & \multicolumn{2}{|c|}{$13.1( \pm 6.2)$} & \multicolumn{2}{|c|}{$0.798 \ddagger^{\star}$} \\
\hline $\mathrm{p}$-value & \multicolumn{2}{|c|}{$0.728 \dagger$} & \multicolumn{2}{|c|}{$0.050 十^{\star}$} & & & \multicolumn{2}{|c|}{$0.700 \dagger$} & \multicolumn{2}{|c|}{$0.019 十^{\star}$} & & \\
\hline \multicolumn{13}{|c|}{ Pelvic stability (Trendelenburg test) - in degrees } \\
\hline & \multicolumn{6}{|c|}{ RLL } & \multicolumn{6}{|c|}{ LLL } \\
\hline & \multicolumn{2}{|c|}{ Initial evaluation } & \multicolumn{2}{|c|}{ Final evaluation } & \multicolumn{2}{|c|}{$p$ value } & \multicolumn{2}{|c|}{ Initial evaluation } & \multicolumn{2}{|c|}{ Final evaluation } & & lue \\
\hline SMTG & 176 & $=1.6)$ & 177 & (1.4) & 0.0 & $27^{\star}$ & 174 & $\pm 3.1)$ & 176( & 2.1) & & $5 \ddagger^{\star}$ \\
\hline CG & 177 & =1.7) & 176 & =1.9) & & $4 \ddagger$ & 175 & $\pm 2.9)$ & 174( & 3.6) & & $8 \ddagger^{\star}$ \\
\hline$p$-value & 0.3 & $1+$ & 0.3 & $33+$ & & & & $9 十^{\star}$ & 0.1 & & & \\
\hline & & & & Dynam & balance & Single ho & test) - ir & degrees & & & & \\
\hline & & & $\mathbf{R}$ & $L$ & & & & & & & & \\
\hline & & 1 - Impuls & & & 2 - Landir & & & 1 - Impuls & & & 2 - Landi & \\
\hline & IE & $\mathrm{FE}$ & $\mathrm{p}$-value & IE & $\mathrm{FE}$ & $p$-value & IE & $\mathrm{FE}$ & $p$-value & IE & $\mathrm{FE}$ & $\mathrm{p}$-value \\
\hline SMTG & $\begin{array}{c}161 \\
( \pm 12.2)\end{array}$ & $\begin{array}{c}172 \\
( \pm 2.8)\end{array}$ & $0.036 \neq^{\star}$ & $\begin{array}{c}169 \\
( \pm 5.5)\end{array}$ & $\begin{array}{c}176 \\
( \pm 1.8)\end{array}$ & $0.050 \ddagger^{\star}$ & $\begin{array}{c}166 \\
( \pm 5.3)\end{array}$ & $\begin{array}{c}171 \\
( \pm 7.2)\end{array}$ & $0.047 \ddagger^{\star}$ & $\begin{array}{c}169 \\
( \pm 5,9)\end{array}$ & $\begin{array}{c}174 \\
( \pm 4.5)\end{array}$ & $0.050 \ddagger^{\star}$ \\
\hline CG & $\begin{array}{c}169 \\
( \pm 8.3)\end{array}$ & $\begin{array}{c}164 \\
( \pm 10.4)\end{array}$ & $0.167 \ddagger$ & $\begin{array}{c}173 \\
( \pm 2.8)\end{array}$ & $\begin{array}{c}170 \\
( \pm 4.3)\end{array}$ & $0.122 \ddagger$ & $\begin{array}{c}166 \\
( \pm 9.2)\end{array}$ & $\begin{array}{c}164 \\
( \pm 10.6)\end{array}$ & $0.314 \ddagger$ & $\begin{array}{c}172 \\
( \pm 1,9)\end{array}$ & $\begin{array}{c}169 \\
( \pm 6.1)\end{array}$ & $0.139 \ddagger$ \\
\hline $\mathrm{p}$-value & $0.223 \dagger$ & $0.093+$ & & & & & $1.000 \dagger$ & $0.119 \dagger$ & & $0.334 \dagger$ & $0.168 \dagger$ & \\
\hline
\end{tabular}

Note: $p$-value for the Bonferroni post hoc test: intergroup $(\dagger)$ and intragroup $(\ddagger)$. " Indicates a significant difference. 


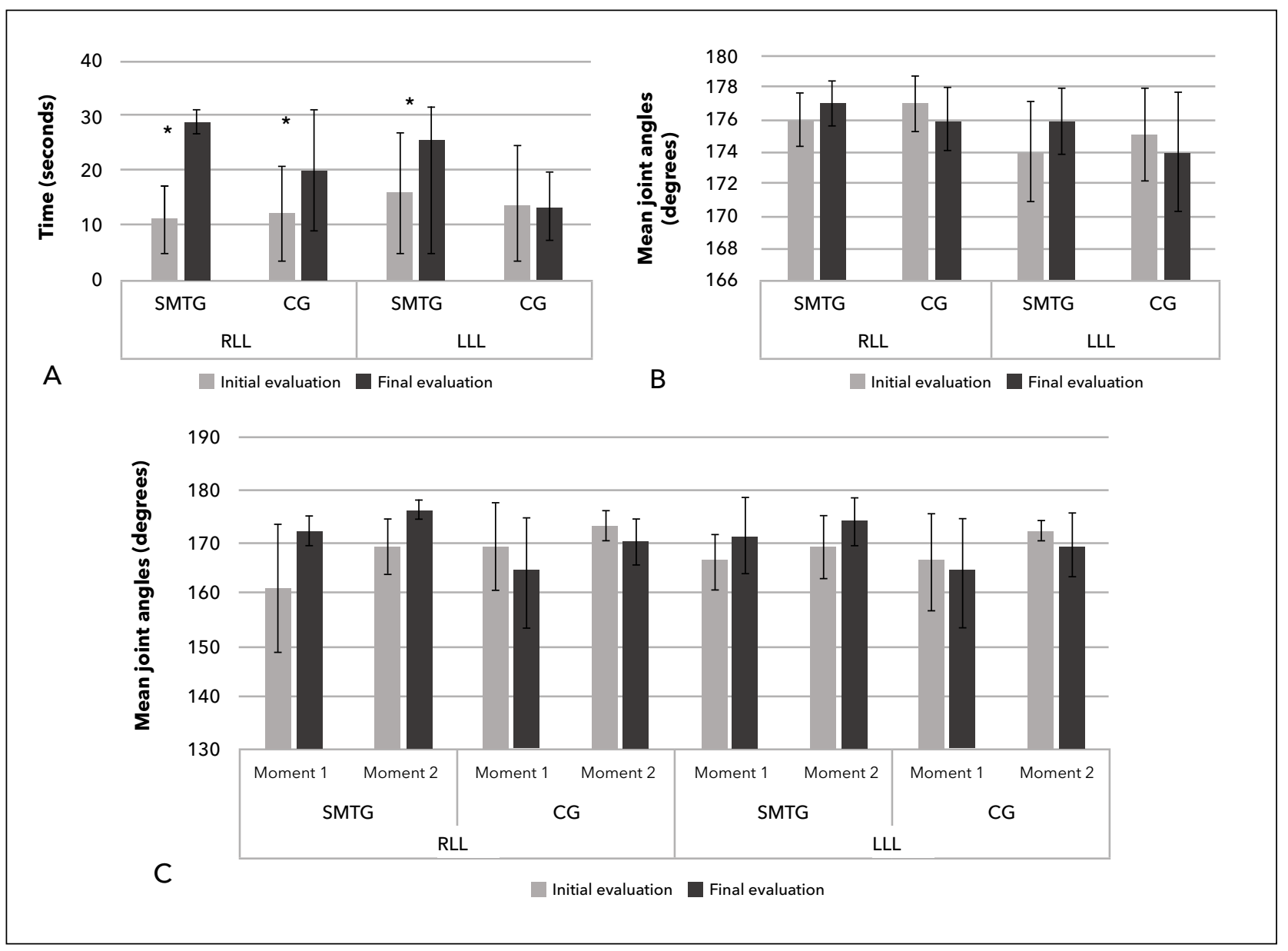

Figure 2 - A: Mean and standard deviation of the time spent on the single-leg stance (in seconds) for the sensorimotor training group (SMTG) and control group (CG) in the initial and final evaluations of the right (RLL) and left lower limbs (LLL). *Indicates significant difference. B: Mean and standard deviation of the measurements of joint angles (pelvic alignment) when performing the Trendelenburg test for the SMTG and CG at the initial and final evaluation of the RLL and LLL. C: Mean and standard deviation of the measurements of joint angles (knee valgus) when performing the hop test at the first (impulsion) and second moments (landing) for the SMTG and CG in the initial and final evaluations of the RLL and LLL.

\section{Dynamic balance - Hop test}

For the joint angle, which represents the knee valgus, the statistical analysis did not indicate a significant difference between groups ( $p=0.923$ ) and evaluations $(p=0.725)$; nevertheless, it revealed a significant difference for interaction between the groups and evaluations $(p=0.008)$. This interaction demonstrates different behaviors in the groups, specifically higher joint angles in the SMTG, thus demonstrating greater alignment of the lower limbs during the jump impulse and landing. The lower joint angles were maintained in the $C G$, indicating lower alignment of both lower limbs during the impulse and landing of the jump. The behavior of both groups in this test, before and after the intervention, is shown in Figure 2C, and Table 3 lists the mean and standard deviation for joint angles at moments 1 (impulsion) and 2 (landing) during the hop test in both groups and evaluations, followed by the $p$ value of intergroup and intragroup analyses by the Bonferroni post hoc test.

In the initial evaluation, the post hoc tests indicated no significant difference between the CG and SMTG for the joint angle of the RLL and the LLL at the moments of impulsion ( $p=0.223$ and $p=1.000$, respectively) and landing ( $p=0.163$ and $p=0.334$, respectively). However, in the final evaluation, the post hoc analyses indicated 
a significant difference between the CG and SMTG for the joint angle of the RLL at the moment of landing $(p=0.012)$, albeit there was no significant difference in RLL at the moment of impulsion ( $p=0.093$ ) or for the LLL at the moment of impulsion $(p=0.119)$ and landing $(p=0.168)$. Furthermore, the post hoc tests indicated a significant difference for the SMTG between the initial and final evaluations for the RLL and LLL joint angle at the moment of impulsion ( $p=0.036$ and $p=0.047$, respectively) and landing ( $p=0.05$ for both). For the $C G$, however, the post hoc tests did not show any significant difference between the initial and final evaluations for the joint angle of the RLL and LLL at the moments of impulsion ( $p=0.167$ and $p=0.314$, respectively) and landing $(p=0.122$ and $p=0.139$, respectively).

\section{Discussion}

This study proposed to investigate the effects of sensorimotor training on $10-\mathrm{km}$ street runners. After the 16 interventions of the proposed training protocol, the athletes showed improved static balance in only one of the lower limbs in dynamic balance and no improvement in lumbopelvic stability. These facts can be observed, respectively, in the increased length of stay in the singleleg stance and increased joint angles, which approached $180^{\circ}$ in the right lower limb, indicating better joint alignment at the moment of impulsion and landing, and, finally, in the lack of angular change of the pelvis in the single-leg stance. In addition to the significant difference that only occurred in the static balance, the effect size in this item in the right and left lower limbs was large and above average, respectively. In the dynamic balance at the moment of landing, such an effect was also considered significant, indicating the relevance of the gains found herein.

There is no doubt about the high prevalence of lower limb injuries in runners because the impact force at this location during training can reach three times the body mass. ${ }^{2,11,12}$ Such impact can contribute to injuries, primarily when associated with intrinsic factors such as the knee joint. The knee joint is commonly affected by injuries in runners due to its anatomical complexity, ${ }^{2,3,11,13,14}$ which propitiates a natural instability. ${ }^{15,16}$ Furthermore, factors such as local muscle weakness and overtraining may favor hip joint injuries (e.g., gluteus medius tendinopathy). ${ }^{12}$ This condition may affect individuals' functionality gain and activity level and, consequently, their quality of life. ${ }^{17}$ Thus, in order to avoid the removal of athletes from sports, future medical expenses, and the consequent impact on quality of life resulting from injuries, it is pivotal to identify the deficits that these athletes present to develop preventive interventions for this population.

The balance system aims to allow the minimum displacement of the body's center of gravity, thus improving postural control. ${ }^{18}$ Postural control, in turn, allows an adequate posture to perform the specific movements required by the sport. ${ }^{19}$ Individuals with greater postural sway, and therefore poorer balance, were seven times more likely to suffer an ankle sprain compared to individuals without this sway. ${ }^{4}$ This is because the compliance of several factors, especially proprioception, is essential for balance to be adequate. Proprioception means awareness of position, movement, and resistance of objects related to the body, ${ }^{20}$ and it is essential for joint stabilization. ${ }^{21}$ Proprioceptive information comes from muscle (muscle spindle) and tendon (Golgi tendon organ) receptors of different musculoskeletal structures. ${ }^{5}$ This information generated by the mechanoreceptors is processed in the central nervous system and generates forms of muscle activation for joint stabilization, which optimizes dynamic joint stabilization and postural control. ${ }^{5}$ When this mechanism is altered (i.e., injuries), processing does not occur adequately and, therefore, joint stabilization may not occur effectively, intensifying the risk of injuries during sports activities. ${ }^{5}$ Given this scenario, when assessing static and dynamic balance, especially during single-leg hopping, which is a constant movement during running exercises, it is possible to identify deficits in postural control and dynamic joint stabilization, respectively.

In addition, while running, the lower limb joints are constantly used and, for these movements to occur adequately, the lumbopelvic complex has the role of providing stability. ${ }^{21}$ This fact occurs because this region acts as a place of transmission of the forces generated in the lower limb to the trunk during running, therefore requiring good stability to reduce injuries. ${ }^{11}$ Postural changes in these locations, including pelvic anteversion and lumbar hyperlordosis, can overload the posterior facet joints of the lumbar spine and, when added to the overload from the repetitive impact of running, cause arthrosis in this region. ${ }^{22,23}$ Therefore, evaluating the stability of the lumbopelvic complex and interventions that seek to optimize the function of this region are indispensable. 
Given the importance of correcting the deficits described herein, this study used sensorimotor training due to its effectiveness in improving sensorimotor function. ${ }^{24}$ This training protocol aims to facilitate proprioceptive information input to the central nervous system so that the response occurs more quickly and adequately, improving joint stabilization and coordination. ${ }^{25,26}$ Hübscher et al. ${ }^{5}$ reported that sensorimotor training with balance and sport-specific exercises effectively reduced the risk of lower limb injuries, thus corroborating the findings of our study, which used exercises that replicated movements required during running.

Given the above, this study proposed an evaluation using easily applicable tests that allowed the neuromuscular control to be evaluated even in static situations and experimental laboratory conditions while employing software available to health professionals. Moreover, the proposal of sensorimotor training using resources that are generally easily accessible to professionals was met. Nonetheless, the main limitation was the number of participants, as there were only seven athletes in each experimental group. For this reason, despite the knowledge of the effects of sensorimotor training on the dynamic and static balance of street runners, further research must be carried out and with a larger number of athletes and a more extended period of intervention with sensorimotor training to verify the effects on static balance and lumbopelvic stability.

\section{Conclusion}

The proposed sensorimotor training protocol led to overall improvements, especially in static balance, in the athletes of the sensorimotor training group. Nevertheless, the control group did not present alterations in static and dynamic balance or pelvic stability.

\section{Acknowledgments}

The authors would like to thank the National Council for Scientific and Technological Development (CNPq) (PIBIC 2018/22153), the PUC Minas Research Incentive Fund (FIP 2019/22398), and Gabriel Signori for all his help with the texts.

\section{Authors'contribution}

All authors contributed to the conception and design of the study, analysis and interpretation of results, writing and critical review of the manuscript and approval of the final version, being responsible for all aspects of the study, including its accuracy and integrity.

\section{References}

1. Yeung SS, Yeung EW, Gillespie LD. Interventions for preventing lower limb soft-tissue running injuries. Cochrane Database Syst Rev. 2011;(7):CD001256. DOI

2. Rangel GMM, Farias JM. Incidência de lesões em praticantes de corrida de rua no município de Criciúma, Brasil. Rev Bras Med Esporte. 2016;22(6):496-500. DOI

3. Pileggi P, Gualano B, Souza M, Caparbo VF, Pereira RMR, Pinto ALS, et al. Incidência e fatores de risco de lesões osteomioarticulares em corredores: um estudo de coorte prospectivo. Rev Bras Educ Fis Esporte. 2010;24(4):453-62. DOI

4. McGuine TA, Greene JJ, Best T, Leverson G. Balance as a predictor of ankle injuries in high school basketball players. Clin J Sport Med. 2000;10(4):239-44. DOI

5. Hübscher M, Zech A, Pfiefer K, Hänsel F, Vogt L, Banzer W. Neuromuscular training for sports injury prevention: a systematic review. Med Sci Sports Exerc. 2010;42(3):413-21. DOI

6. Baldaço FO, Cadó VP, Souza J, Mota CB, Lemos JC. Análise do treinamento proprioceptivo no equilíbrio de atletas de futsal feminino. Fisioter Mov. 2010;23(2):183-92. DOI

7. Springer BA, Marin R, Cyhan T, Roberts H, Gill NW. Normative values for the unipedal stance test with eyes open and closed. $J$ Geriatr Phys Ther. 2007;30(1):8-15. DOI

8. Hardcastle P, Nade S. The significance of the Trendelenburg test. J Bone Joint Surg Br. 1985;67(5):741-6. PubMed

9. Gogu S, Gandbhir VN. Trendelenburg Sign. In: StatPearls. Treasure Island (FL): StatPearls Publishing; 2021. Full text link 
10. Noyes FR, Barber SD, Mangine RE. Abnormal lower limb symmetry determined by function hop tests after anterior cruciate ligament rupture. Am J Sports Med. 1991;19(5):513-8. $\mathrm{DOI}$

11. Borel WP, Elias Filho J, Diz JBM, Moreira PF, Veras PM, Catharino LL, et al. Prevalence of injuries in Brazilian recreational street runners: Meta-analysis. Rev Bras Med Esporte. 2019;25(2):161-7. DOI

12. Geraci Jr MC, Brown W. Evidence-based treatment of hip and pelvic injuries in runners. Phys Med Rehabil Clin N Am. 2005;16(3):711-47. DOI

13. Silva LR, Pimentel MPBS, Silva VM, Nascimento LL. Qualidade de vida e incidência de lesões musculoesqueléticas em corredores de rua. Movimenta. 2019;2(2):238-46. Full text link

14. van Gent RN, Siem D, van Middelkoop M, van Os AG, BiermaZeinstra SM, Koes BW. Incidence and determinants of lower extremity running injuries in long distance runners: a systematic review. Br J Sports Med. 2007;41(8):469-80. DOI

15. Bulla HA. Aplicação da baropodometria na avaliação da correlação entre os tipos de pés e a incidência de lesões nos joelhos [master's thesis]. São José dos Campos: Universidade do Vale do Paraíba; 2010.

16. Majewski M, Susanne $H$, Klaus S. Epidemiology of athletic knee injuries: A 10-year study. Knee. 2006;13(3):184-8. DO।

17. Grimaldi A, Fearon A. Gluteal tendinopathy: integrating pathomechanics and clinical features in its management. J Orthop Sports Phys Ther. 2015;45(11):910-22. DOI
18. Pollock AS, Durward BR, Rowe PJ, Paul JP. What is balance? Clin Rehabil. 2000;14(4):402-6. DOI

19. Bednarczuk G, Wiszomirska I, Rutkowska I, Skowroński W. Effects of sport on static balance in athletes with visual impairments. JSports Med Phys Fitness. 2019;59(8):1319-27.DOI

20. Botelhos DC, Bonfim TR. Influência da informação sensorial adicional no treinamento sensório-motor. Fisioter Pesqui. 2012;19(3):268-74. DOI

21. Rivera CE. Core and lumbopelvic stabilization in runners. Phys Med Rehabil Clin N Am. 2016;27(1):319-37. DOI

22. Miranda SF, Corotti VGP, Menegaz P, Ueda W, Vialle EN, Vialle LR. Influence of total hip arthroplasty on sagittal lumbarpelvic balance: Evaluation of radiographic parameters. Rev Bras Ortop (Sao Paulo). 2019;54(6):657-64. DOI

23. Schache AG, Blanch PD, Murphy AT. Relation of anterior pelvic tilt during running to clinical and kinematic measures of hip extension. Br J Sports Med. 2000;34(4):279-83. DOI

24. Aman JE, Elangovan N, Yeh IL, Konczak J. The effectiveness of proprioceptive training for improving motor function: a systematic review. Front Hum Neurosci. 2015;8:1075. DOI

25. Ahmad I, Noohu MM, Verma S, Singla D, Hussain ME. Effect of sensorimotor training on balance measures and proprioception among middle and older age adults with diabetic peripheral neuropathy. Gait Posture. 2019;74:114-20. DOI

26. Cohen M, Abdalla RJ. Lesões nos esportes: diagnóstico, prevenção, tratamento. Rio de Janeiro: Revinter; 2003. 